\title{
Protein-Controlled Actuation of Dynamic Nucleic Acid Networks Using Synthetic DNA Translators
}

ALESSANDRO BERTUCCI, Alessandro Porchetta, Erica Del Grosso, Tania Patiño, Andrea Idili, Francesco Ricci

Submitted date: 04/06/2020 - Posted date: 05/06/2020

Licence: CC BY-NC-ND 4.0

Citation information: BERTUCCI, ALESSANDRO; Porchetta, Alessandro; Grosso, Erica Del; Patiño, Tania; Idili, Andrea; Ricci, Francesco (2020): Protein-Controlled Actuation of Dynamic Nucleic Acid Networks Using Synthetic DNA Translators. ChemRxiv. Preprint. https://doi.org/10.26434/chemrxiv.12424658.v1

Integrating dynamic DNA nanotechnology with protein-controlled actuation will expand our ability to process molecular information. We have developed a strategy to actuate strand displacement reactions using DNA-binding proteins by engineering synthetic DNA translators that convert specific protein-binding events into trigger inputs through a programmed conformational change. We have constructed synthetic DNA networks responsive to two different DNA-binding proteins, TATA-binding protein and Myc-Max, and demonstrated multi-input activation of strand displacement reactions. We finally achieved protein-controlled regulation of a synthetic RNA and of an enzyme through artificial DNA-based communication, showing the potential of our molecular system in performing further programmable tasks.

File list (1)

Translator_Chemrxiv.pdf (23.42 MiB)

view on ChemRxiv • download file 


\title{
Protein-Controlled Actuation of Dynamic Nucleic Acid Networks
}

\section{Using Synthetic DNA Translators}

Alessandro Bertucci, ${ }^{*}{ }^{, 1}$ Alessandro Porchetta, ${ }^{1}$ Erica Del Grosso, ${ }^{1}$ Tania Patiño, ${ }^{1}$ Andrea Idili, ${ }^{2}$ Francesco Ricci ${ }^{1, *}$

${ }^{1}$ Chemistry Department, University of Rome Tor Vergata, Via della Ricerca Scientifica, 00133

Rome, Italy. ${ }^{2}$ Catalan Institute of Nanoscience and Nanotechnology (ICN2), Campus UAB, Bellaterra, 08193 Barcelona, Spain.

\begin{abstract}
Integrating dynamic DNA nanotechnology with protein-controlled actuation will expand our ability to process molecular information. We have developed a strategy to actuate strand displacement reactions using DNA-binding proteins by engineering synthetic DNA translators that convert specific protein-binding events into trigger inputs through a programmed conformational change. We have constructed synthetic DNA networks responsive to two different DNA-binding proteins, TATA-binding protein and Myc-Max, and demonstrated multi-input activation of strand displacement reactions. We finally achieved protein-controlled regulation of a synthetic RNA and of an enzyme through artificial DNAbased communication, showing the potential of our molecular system in performing further programmable tasks.
\end{abstract}




\section{INTRODUCTION}

Information processing in living systems relies on the communication between different biomolecules. The whole genetic machinery, for example, is based on the dynamic interplay between proteins, DNA and RNA: direct protein-DNA communication is achieved by DNAbinding proteins such as transcription factors that recognize specific DNA domains called consensus sequences and regulate the rate of transcription of genes into messenger RNA. ${ }^{[1]}$ In an effort to artificially recreate Nature's language, DNA nanotechnology has translated the governing principles of nucleic acid hybridization into programmable bioinspired systems that can be tuned in space and time..$^{[2-4]}$ Toehold-mediated strand displacement is arguably the most simple, robust and versatile tool available to generate dynamic, responsive and transformative higher-order networks in which synthetic DNA oligonucleotides perform programmable tasks with possible applications in synthetic biology, sensing and information processing. ${ }^{[5-10]}$ However, nucleic acid trigger inputs are generally required for upstream activation: this ultimately limits the extent to which DNA-based computation can mediate artificial communication between different species.

Strand displacement reactions actuated by proteins are challenging because they require the implementation of non-trivial binding-induced mechanisms. One clever strategy makes use of proteins as substrates that promote molecular interactions in a confined volume and induce the hybridization between complementary DNA strands through the increase of their local concentration. ${ }^{[11-16]}$ This strategy is however limited by the availability of specific affinity ligands that must be conjugated to the interacting DNA strands and by the need of multiple binding sites on the target protein. Alternatively, protein-responsive sensing technologies and DNAbased architectures have been engineered capitalizing on the natural DNA binding activity of transcription factors. ${ }^{[17-21]}$ This approach is particularly appealing as it allows direct proteinDNA communication bypassing the use of affinity ligands; nevertheless, to date, it has never 
been interfaced with dynamic synthetic DNA systems and harnessed to control DNA-based computation.

Motivated by the above considerations, we report here the rational design of synthetic DNA translators that convert an input protein-binding event into the output activation of an arbitrary biomolecular system (Figure 1a). We demonstrate that it is possible to tune the output of dynamic DNA networks and to perform multi-input operations using proteins as biochemical inputs and we show that DNA-mediated, artificial communication pathways can be established to allow non-natural regulation of RNA and protein functionality.

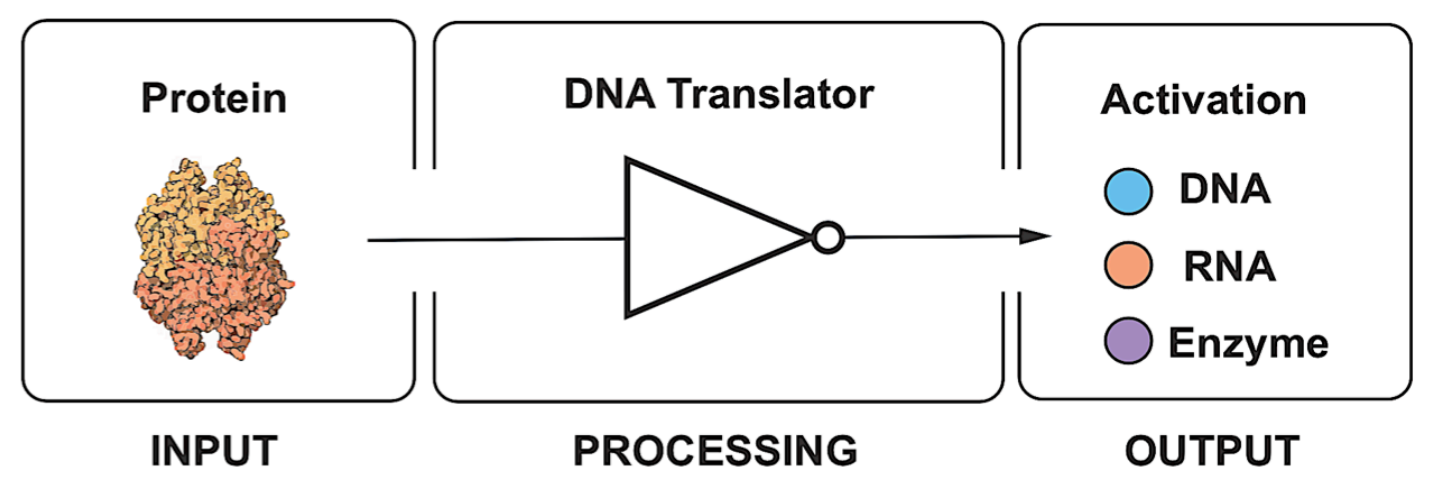

Figure 1. Protein-controlled DNA-based molecular processing. Schematic overview of the artificial communication pathway mediated by a DNA translator that converts a specific protein binding event into the downstream activation of different biomolecular systems. 


\section{RESULTS AND DISCUSSION}

Our protein responsive DNA translator is a synthetic DNA sequence encoding the double stranded consensus sequence specifically recognized by a DNA-binding protein and a single stranded input sequence able to initiate a toehold strand displacement reaction. We have rationally designed such DNA translator to be in a thermodynamic equilibrium between two mutually exclusive conformations. The first structure, more stable, is a double-hairpin structure in which the two portions encoding the double stranded consensus sequence are physically separated and form the two loop regions (red domains, Figure 2a). In this conformation the toehold-binding region of the input strand sequence (orange domain, Figure 2a) is incorporated into one of the two duplex portions so that it is unable to initiate the strand displacement reaction. The second, less favorable, structure is a hairpin conformation in which the double stranded consensus sequence is fully formed and the input strand is free to initiate a strand displacement reaction. The presence of a specific DNA-binding protein recognizing its cognate consensus sequence in the DNA translator is then expected to shift such thermodynamic equilibrium towards the second "active" conformation through a populationshift mechanism. ${ }^{[18,22]}$ We initially designed a DNA translator responsive to TATA binding protein (TBP), a transcription factor ubiquitously present in eukaryotic cells. ${ }^{[23]}$ The thermodynamic switching equilibrium constant $\left(\mathrm{K}_{\mathrm{S}}\right)$ of the DNA translator determines the TBPinduced conformational transition and therefore will affect the efficiency of the strand displacement reaction. In order to optimize the input-output behavior, we have then engineered a set of five TBP-responsive translators (TBP-Translators) with different predicted switching equilibrium constants $\mathrm{K}_{\mathrm{S}}$ (Figure 2a, full sequences reported in the $\mathrm{SI}$ ). 
a
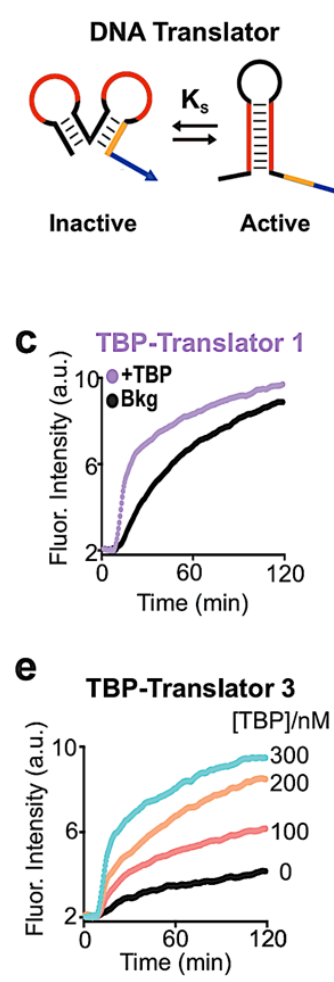

nactive conformation predicted stability

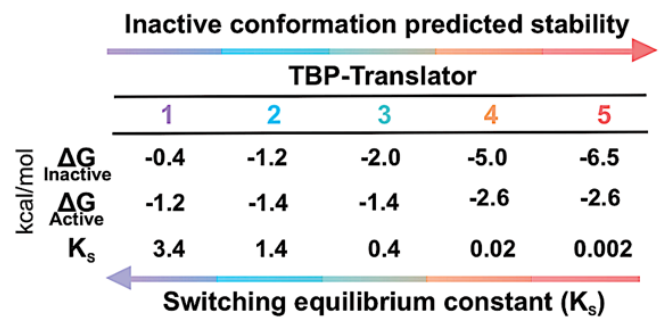

TBP-Translator 2

$10+$ +TBP

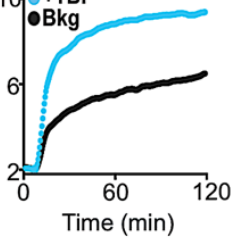

TBP-Translator 3

TBP-Translator 4
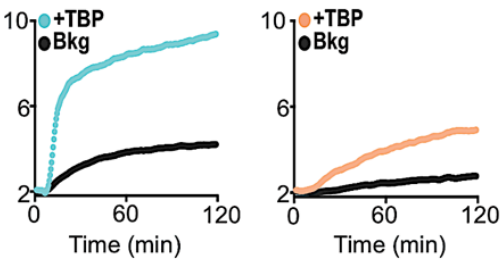

g

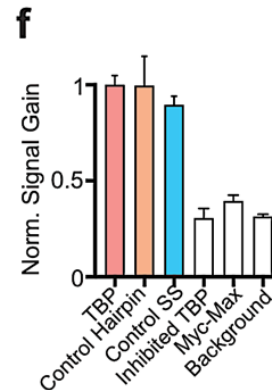

b TATA

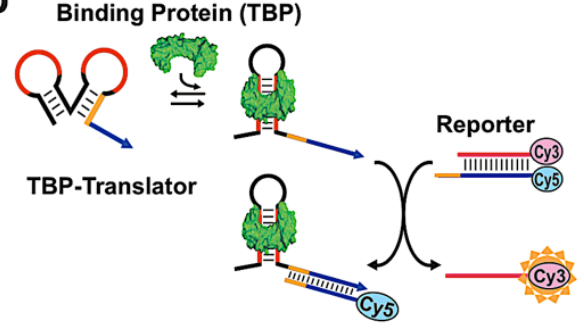

TBP-Translator 5 d
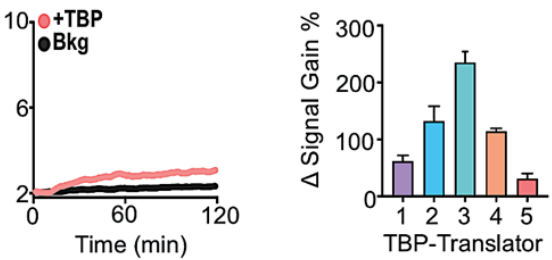

h MYX-Translator i

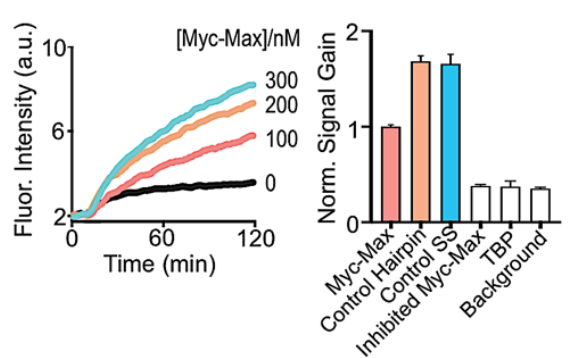

Figure 2. Protein-actuated DNA strand displacement using synthetic protein-responsive DNA translators. (a) A TBP-controlled DNA translator (TBP-Translator) is in thermodynamic equilibrium between two mutually exclusive conformations (active and inactive). The table reports the predicted thermodynamic stability and switching equilibrium constant $\left(\mathrm{K}_{\mathrm{S}}\right)$ of the two conformations for a set of different TBP-Translators. (b) TBP-actuated strand displacement using the TBP-Translator. (c) Kinetic profiles of strand displacement reactions in the presence (+TBP) or absence (Bkg) of TBP $(300 \mathrm{nM})$ obtained in an equimolar solution of TBP-Translator and reporter duplex (30 nM). (d) $\Delta$ Signal Gain \% obtained for each TBP-Translator, calculated as the difference between the signal gain \% of the TBP-controlled reaction and the one relative to the background ( $n=3$, mean + standard error of the mean, SEM). (e) Modulation of the strand displacement output signal using TBP-Translator 3 in presence of different concentrations of TBP. (f) Normalized signal gains obtained with TBP (300 nM), a control hairpin invader (Control hairpin, $30 \mathrm{nM}$ ) and a single-stranded invader (Control SS, $30 \mathrm{nM}$ ). Signal gains observed with TBP in the presence of saturating concentrations of the consensus sequence (Inhibited TBP) and with a non-specific protein (i.e. Myc-Max, $300 \mathrm{nM}$ ) are also shown together with the background signal $(n=3$, mean + SEM). (g) Myc-Max-actuated strand displacement using a Myc-Max-responsive DNA translator (MYX-Translator). (h) Modulation of the strand displacement output signal using MYX-Translator in the presence of different concentrations of Myc-Max. (i) Normalized signal gains obtained with Myc-Max (300 nM), a control hairpin invader (30 $\mathrm{nM}$ ) and a single-stranded invader (30 nM). Signal gains observed with Myc-Max in the presence of saturating concentrations of the consensus sequence (Inhibited Myc-Max) and with a nonspecific protein (i.e. TBP, $100 \mathrm{nM}$ ) are also shown together with the background signal $(n=3$, mean + SEM). 
More specifically, we rationally varied the GC/AT content of the translator portions not involved in the protein recognition event to finely tune the predicted standard free energies of the two switching conformations (Figure SI1). As a reporter system of the strand displacement reaction, we used a DNA duplex (30 nM) equipped with an optical pair (Сy3-Сy5) and monitored the progression of the strand displacement reaction over time by following the increase in Cy3 fluorescence intensity (Figure 2b). Each of the five TBP-Translators was tested in the absence and presence of input TBP. The translators showed different degrees of background signal, caused by the uncontrolled initiation of the strand displacement reaction, as a result of their varying thermodynamic stabilities (Figure 2c). The best trade-off between TBP-induced strand displacement and non-specific background ( $\Delta$ Signal Gain \% $=235 \pm 19$ ) was achieved using the TBP-Translator $3\left(K_{S}=0.4\right)$ (Figure $2 d$ and SI2). We thus focused on this translator for a further characterization of the system. By using different concentrations of TBP, it was possible to finely modulate the extent of the strand displacement reaction (Figure 2e). The efficiency of the TBP-responsive strand displacement reaction was evaluated by benchmarking against the fluorescence outputs obtained using equivalent concentrations of either a single stranded input sequence (Control SS, Figure 2f) or a hairpin structure mimicking the TBP-Translator active conformation when bound to TBP (Control hairpin, Figure 2f), and no significant differences were found. To have further validation of the binding-induced mechanism underlying the strand displacement reaction, we ran a competitive assay in which we pre-incubated TBP with an excess of a DNA hairpin bearing the complete TBP-binding domain. In this case, TBP-mediated strand displacement reaction did not occur, and we only registered a signal indistinguishable from the background signal (Figure $2 f$ and $S I 3$ ). Additional proof of the interaction between TBP and TBP-Translator 3 was achieved by conducting a gel electrophoresis analysis of the mono- and multi-molecular species involved in the strand 
displacement reaction (Figure SI4). The TBP-Translator is also specific: no signal was observed with an unrelated DNA-binding protein recognizing a different consensus sequence (Myc-Max, Figure $2 f$ and SI5).

In order to demonstrate the generality of our approach, we rationally designed a DNA translator responsive to Myc-Max complex, another transcription factor that is clinically relevant in oncology. ${ }^{[24]}$ We have engineered this Myc-Max-responsive DNA translator, hereafter referred to as MYX-Translator, following the design rules conducted with the previously described TBP-controlled system (Figure $2 \mathrm{~g}$, SI6). More specifically, we have rationally designed a translator that interconverts between an active and inactive mutually exclusive conformation with a predicted $\mathrm{K}_{\mathrm{S}}$ of 0.4 . The Myc-Max-controlled strand displacement reaction observed with this translator in presence of a saturating concentration of the target protein provided a $\Delta$ Signal Gain $\%$ of $169 \pm 39$, with a signal-to-noise ratio of 2.0 \pm 0.4 (Figure SI6). Varying the concentration of Myc-Max allowed for modulating the strand displacement output, similarly to what observed with the TBP-controlled system (Figure 2h). The Myc-Max-actuated process yielded around $75 \%$ of the signal obtained using comparable concentrations ( $30 \mathrm{nM}$ ) of either a control single-stranded input sequence or a hairpin structure mimicking the active MYX-Translator conformer (Figure 2i). This lower relative efficiency may be ascribed to a less effective binding of Myc-Max to the MYX-Translator compared to that of TBP to its cognate translator (Figure 2f), or a less efficient strand invasion process possibly caused by steric hindrance effects. ${ }^{[25]}$ Pre-incubation of Myc-Max with an excess of a DNA hairpin displaying the double stranded Myc-Max consensus sequence resulted in the inhibition of the Myc-Max-induced strand displacement reaction (Figure $2 \mathrm{i}$ and SI7). To investigate cross-reactivity, we exposed the Myc-Max-controlled network to TBP. We found that exposure to TBP $100 \mathrm{nM}$ generated signals not significantly different from the background (Figure $2 \mathrm{i}$ and SI8). 
Our protein-controlled DNA translators specifically respond to their cognate input proteins and allow the orthogonal activation of strand displacement reactions in a multi-strand DNA system. To demonstrate this, we designed a multi-input network presenting simple binary logic composed of two reporter DNA duplexes (30 nM) with distinct fluorescence emission windows and responsive to two different protein-actuated DNA translators, i.e. TBP and Myc-Max (Figure 3 and Figure SI9). Our molecular network can be orthogonally controlled in the same solution by TBP and Myc-Max in a programmable, multi-input manner (Figure 3).
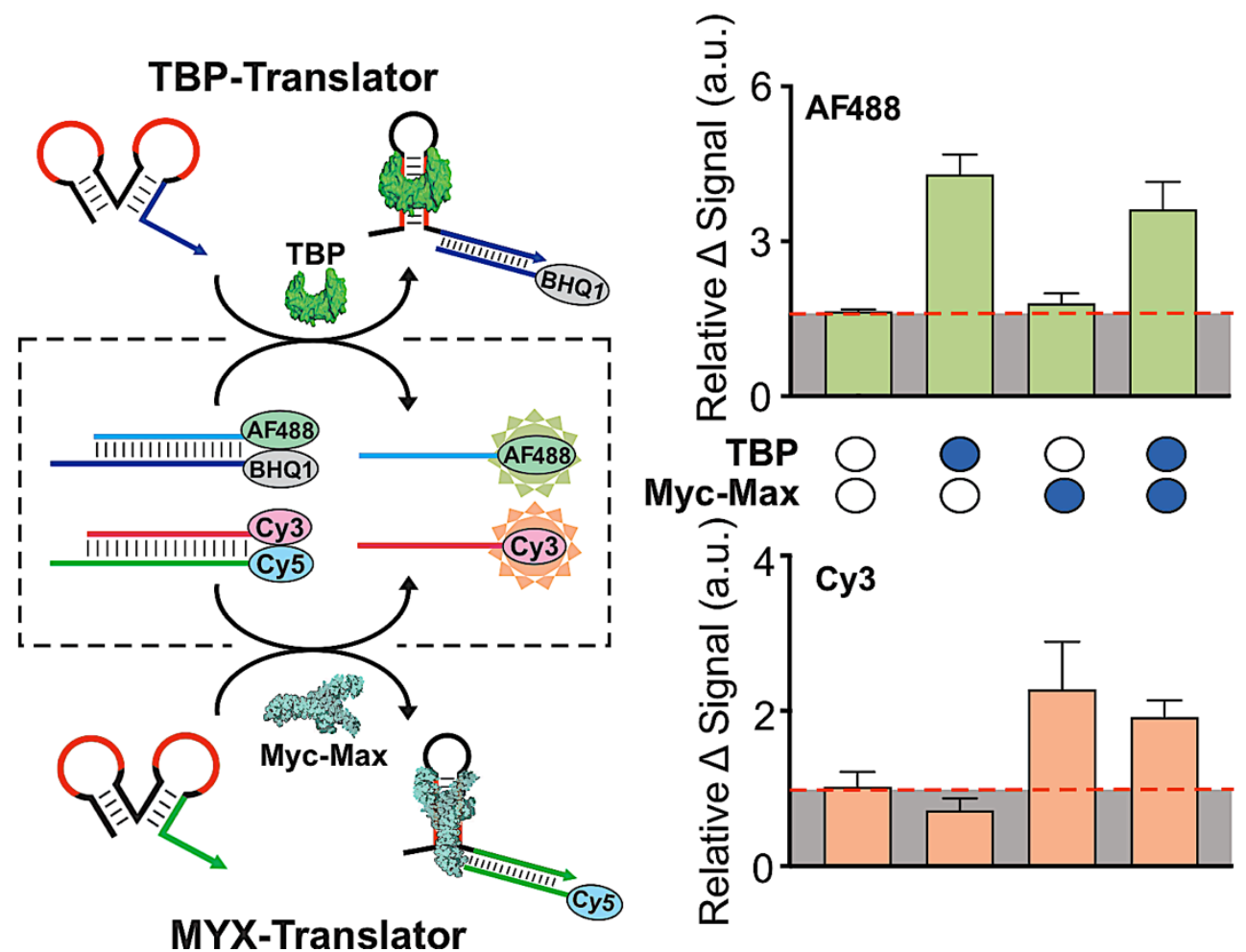

Figure 3. Multi-input, orthogonal activation of protein-controlled DNA translators. A TBPresponsive strand displacement reaction produces a fluorescence maximum at $\lambda=516 \mathrm{~nm}$ (AF488) while a Myc-Max-responsive system peaks at $\lambda=565 \mathrm{~nm}$ (Су3). The two networks are orthogonally controlled in the same solution using the relevant protein inputs (TBP $100 \mathrm{nM}$, Myc-Max $300 \mathrm{nM}$ ). The relative $\Delta$ Signal is the difference between the fluorescence intensity at $t=60$ min and the initial fluorescence signal of each reporter duplex $(n=3$, mean $+S E M)$.

To further investigate the capability of our platform to support advanced DNA-based computation and to enable artificial communication between non-naturally related 
biomolecules, we set out to perform protein-induced activation of a functional RNA structure. To do this, we focused on a synthetic fluorogenic RNA aptamer (Mango III) that yields a bright fluorescence signal upon binding to a thiazole orange (TO-1) dye ${ }^{[26,27]}$ We prevented folding of such RNA aptamer into its optically active conformation by using a blocking RNA strand that hybridizes to a critical region of the aptamer. Displacement of the blocking strand operated by an ad hoc designed TBP-activated DNA translator (TBP-Mango-translator) allows the correct folding of the active RNA aptamer structure, which generates a fluorescence signal (Figure $4 a) .{ }^{[28]}$

Using $100 \mathrm{nM}$ of TBP-Mango-translator in the presence of TBP (600 nM), we successfully achieved TBP-controlled folding and activation of the Mango aptamer (Figure 4b). Of note, the TBP-induced Mango activation process was as efficient as when using a stable DNA hairpin structure mimicking the active conformation of the TBP-Mango-translator (Figure SI10).

In a second application, we engineered a molecular network in which the upstream TBP input is processed into the downstream regulation of the proteolytic activity of thrombin (Figure 4c). Human $\alpha$-thrombin is a protein that plays an important role in the coagulation cascade by cleaving soluble fibrinogen into insoluble fibrin. ${ }^{[29]}$ Its proteolytic activity can be inhibited by a 15-mer DNA aptamer that binds to the fibrinogen-interacting site with nanomolar affinity. ${ }^{[30]}$ Inspired by the molecular design proposed by Ikebukuro and coworkers, ${ }^{[31]}$ we have engineered a thrombin DNA aptamer equipped with a stem-loop handle that allows for controlling the aptamer folding and therefore its inhibitory activity (Figure 4c and SI11). We incorporated a DNA sequence complementary to this loop portion into the structure of a TBPresponsive translator, hereafter referred to as TBP-Thrombin-Translator. Upon binding of TBP, this translator undergoes structural conversion and exposes the active input strand: this causes abrogation of the inhibitory activity of the aptamer by inducing its unfolding through opening of the stem-loop handle (Figure 4c and SI11). 

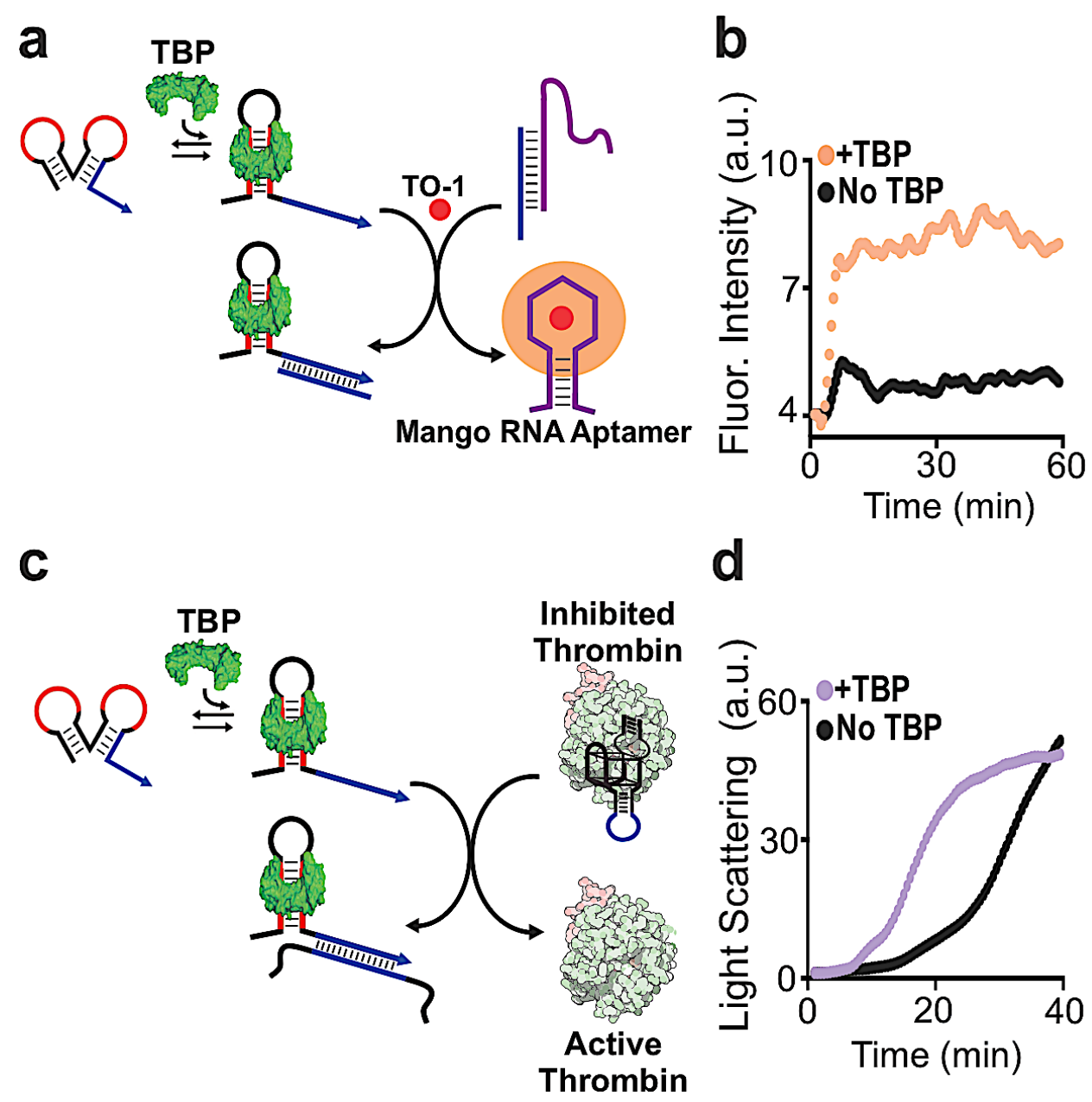

Figure 4. Artificial protein-RNA and protein-protein communication through synthetic DNA translators. (a) Schematic representation of TBP-controlled activation of a fluorogenic RNA Mango aptamer. (b) Mango-based fluorescence signal with (+TBP) or without (No TBP) the addition of TBP $(1 \mu \mathrm{M})$ to a solution containing $100 \mathrm{nM}$ of TBP-Mango-Translator and 30 $\mathrm{nM}$ of blocking RNA/Mango aptamer complex. (c) Schematic representation of TBP-controlled regulation of the proteolytic activity of thrombin. (d) Intensity of light scattering due to thrombingenerated fibrin aggregates in the presence (+TBP) or absence (No TBP) of TBP (300 nM) in a solution containing equimolar concentration of TBP-Thrombin-Translator and thrombin aptamer (50 $\mathrm{nM})$ and thrombin (1 $\mathrm{nM})$.

The kinetics of thrombin enzymatic proteolysis was followed by measuring the increase in the scattering of light after fibrinogen $(1 \mathrm{mg} / \mathrm{mL})$ was added to a solution of thrombin $(1 \mathrm{nM})$, which reflects the degree of fibrin agglomeration (coagulation) as a result of fibrinogen cleavage. ${ }^{[32]}$ Our aptamer structure $(50 \mathrm{nM})$ induced significant inhibition of the enzymatic activity upon binding to thrombin, delaying of around 14 minutes the time necessary to obtain 
half of the maximum signal (Figure SI11). After testing our biomolecular network using a model

DNA hairpin input (Figure SI11), we could effectively regulate the enzymatic activity of thrombin using TBP as upstream activator $(300 \mathrm{nM})$, as demonstrated by the significant acceleration of the coagulation process compared to that obtained in a control experiment (Figure 4d).

\section{CONCLUSIONS}

Synthetic DNA-based transducers have been previously designed to mediate artificial communication between proteins that are not natural partners. ${ }^{[4]}$ Our study expands on this concept and proposes new design rules that will allow many other DNA-binding proteins to be utilized as molecular inputs guiding DNA computation and programming. More specifically, we report here the rational design of synthetic DNA translators responsive to specific DNA-binding proteins that allow protein-controlled actuation of nucleic acid-based molecular networks. We demonstrate that this strategy can be used to trigger toehold-mediated strand displacement reactions and to establish artificial protein-RNA and protein-protein communication mediated by DNA-based operations. We envision that additional complex tasks, including controlling 3D self-assembly ${ }^{[33,34]}$ and processing biomolecular information through higher-order circuits, may be performed following this approach, paving the way to new applications in synthetic biology, DNA nanotechnology and life sciences.

\section{Supporting Information}

Materials and methods, DNA and RNA sequences, supplementary figures (PDF).

\section{AUTHOR INFORMATION}

\section{Corresponding Author}


* Alessandro Bertucci - Department of Chemical Sciences and Technologies, University of Rome Tor Vergata, 00133 Rome, Italy. ORCID: 0000-0003-4842-9909.

Email: alessandro.bertucci@uniroma2.it

${ }^{*}$ Francesco Ricci - Department of Chemical Sciences and Technologies, University of Rome Tor Vergata, 00133 Rome, Italy. ORCID: 0000-0003-4941-8646.

Email: francesco.ricci@uniroma2.it

\section{ACKNOWLEDGMENT}

This project received funding from the European Union's Horizon 2020 research and innovation program under the Marie Skłodowska-Curie grant agreement No 704120 (“MIRNANO"). AB was supported by Fondazione Umberto Veronesi. 


\section{REFERENCES}

[1] Badis, G.; Berger, M. F.; Philippakis, A. A.; Talukder, S.; Gehrke, A. R.; Jaeger, S. A.; Chan,

E. T.; Metzler, G.; Vedenko, A.; Chen, X.; et al. Diversity and Complexity in DNA Recognition by Transcription Factors. Science 2009, 324, 1720-1723.

[2] Seeman, N. C.; Sleiman, H. F. DNA Nanotechnology. Nat. Rev. Mater. 2017, 3, 17068.

[3] Hu, Y.; Niemeyer, C. M. From DNA Nanotechnology to Material Systems Engineering. Adv. Mater. 2019, 31, e1806294.

[4] Peri-Naor, R.; Ilani, T.; Motiei, L.; Margulies, D. Protein-Protein Communication and Enzyme Activation Mediated by a Synthetic Chemical Transducer. J. Am. Chem. Soc. 2015, 137, 9507-9510.

[5] Zhang, D. Y.; Seelig, G. Dynamic DNA Nanotechnology Using Strand-Displacement Reactions. Nat. Chem. 2011, 3, 103-113.

[6] Fu, T.; Lyu, Y.; Liu, H.; Peng, R.; Zhang, X.; Ye, M.; Tan, W. DNA-Based Dynamic Reaction Networks. Trends Biochem. Sci. 2018, 43, 547-560.

[7] Qian, L.; Winfree, E.; Bruck, J. Neural Network Computation with DNA Strand Displacement Cascades. Nature 2011, 475, 368-372.

[8] Groves, B.; Chen, Y.-J.; Zurla, C.; Pochekailov, S.; Kirschman, J. L.; Santangelo, P. J.; Seelig, G. Computing in Mammalian Cells with Nucleic Acid Strand Exchange. Nat. Nanotechnol. 2016, 11, 287-294.

[9] Wang, F.; Lv, H.; Li, Q.; Li, J.; Zhang, X.; Shi, J.; Wang, L.; Fan, C. Implementing Digital Computing with DNA-Based Switching Circuits. Nat. Commun. 2020, 11, 121.

[10] Lloyd, J.; Tran, C. H.; Wadhwani, K.; Cuba Samaniego, C.; Subramanian, H. K. K.;

Franco, E. Dynamic Control of Aptamer-Ligand Activity Using Strand Displacement Reactions. ACS Synth. Biol. 2018, 7, 30-37. 
[11] Rossetti, M.; Bertucci, A.; Patino, T.; Baranda Pellejero, L.; Porchetta, A. Programming DNA-Based Systems through Effective Molarity Enforced by Biomolecular Confinement. Chem. Eur. J. 2020, DOI: 10.1002/chem.202001660.

[12] Li, F.; Zhang, H.; Wang, Z.; Li, X.; Li, X.-F.; Le, X. C. Dynamic DNA Assemblies Mediated by Binding-Induced DNA Strand Displacement. J. Am. Chem. Soc. 2013, 135, 2443-2446.

[13] Tang, Y.; Lin, Y.; Yang, X.; Wang, Z.; Le, X. C.; Li, F. Universal Strategy to Engineer Catalytic DNA Hairpin Assemblies for Protein Analysis. Anal. Chem. 2015, 87, 8063-8066.

[14] Porchetta, A.; Ippodrino, R.; Marini, B.; Caruso, A.; Caccuri, F.; Ricci, F. Programmable Nucleic Acid Nanoswitches for the Rapid, Single-Step Detection of Antibodies in Bodily Fluids. J. Am. Chem. Soc. 2018, 140, 947-953.

[15] Engelen, W.; Meijer, L. H. H.; Somers, B.; de Greef, T. F. A.; Merkx, M. AntibodyControlled Actuation of DNA-Based Molecular Circuits. Nat. Commun. 2017, 8, 14473

[16] Ranallo, S.; Sorrentino, D.; Ricci, F. Orthogonal Regulation of DNA Nanostructure SelfAssembly and Disassembly Using Antibodies. Nat. Commun. 2019, 10, 5509.

[17] Heyduk, T.; Heyduk, E. Molecular Beacons for Detecting DNA Binding Proteins. Nat. Biotechnol. 2002, 20, 171-176

[18] Vallée-Bélisle, A.; Bonham, A. J.; Reich, N. O.; Ricci, F.; Plaxco, K. W. Transcription Factor Beacons for the Quantitative Detection of DNA Binding Activity. J. Am. Chem. Soc. 2011, 133, 13836-13839.

[19] Bonham, A. J.; Hsieh, K.; Ferguson, B. S.; Vallée-Bélisle, A.; Ricci, F.; Soh, H. T.; Plaxco, K. W. Quantification of Transcription Factor Binding in Cell Extracts Using an Electrochemical, Structure-Switching Biosensor. J. Am. Chem. Soc. 2012, 134, 3346-3348.

[20] Bertucci, A.; Guo, J.; Oppmann, N.; Glab, A.; Ricci, F.; Caruso, F.; Cavalieri, F. Probing Transcription Factor Binding Activity and Downstream Gene Silencing in Living Cells with a DNA Nanoswitch. Nanoscale 2018, 10, 2034-2044. 
[21] Praetorius, F.; Dietz, H. Self-Assembly of Genetically Encoded DNA-Protein Hybrid Nanoscale Shapes. Science 2017, 355, eaam5488.

[22] Vallée-Bélisle, A.; Ricci, F.; Plaxco, K. W. Thermodynamic Basis for the Optimization of Binding-Induced Biomolecular Switches and Structure-Switching Biosensors. Proc. Natl. Acad. Sci. USA 2009, 106, 13802-13807.

[23] Rowlands, T.; Baumann, P.; Jackson, S. P. The TATA-Binding Protein: A General Transcription Factor in Eukaryotes and Archaebacteria. Science 1994, 264, 1326-1329

[24] Darnell, J. E. Transcription Factors as Targets for Cancer Therapy. Nat. Rev. Cancer 2002, 2, 740-749.

[25] Nair, S. K.; Burley, S. K. X-Ray Structures of Myc-Max and Mad-Max Recognizing DNA. Molecular Bases of Regulation by Proto-Oncogenic Transcription Factors. Cell 2003, 112, 193-205.

[26] Dolgosheina, E. V.; Jeng, S. C. Y.; Panchapakesan, S. S. S.; Cojocaru, R.; Chen, P. S. K.; Wilson, P. D.; Hawkins, N.; Wiggins, P. A.; Unrau, P. J. RNA Mango Aptamer-Fluorophore: A Bright, High-Affinity Complex for RNA Labeling and Tracking. ACS Chem. Biol. 2014, 9, 2412 2420.

[27] Trachman, R. J.; Autour, A.; Jeng, S. C. Y.; Abdolahzadeh, A.; Andreoni, A.; Cojocaru, R.; Garipov, R.; Dolgosheina, E. V.; Knutson, J. R.; Ryckelynck, M.; et al. Structure and Functional Reselection of the Mango-III Fluorogenic RNA Aptamer. Nat. Chem. Biol. 2019, 15, 472-479. [28] Zhong, W.; Sczepanski, J. T. A Mirror Image Fluorogenic Aptamer Sensor for Live-Cell Imaging of MicroRNAs. ACS Sens. 2019, 4, 566-570.

[29] Di Cera, E. Thrombin. Mol. Aspects Med. 2008, 29, 203-254.

[30] Bock, L. C.; Griffin, L. C.; Latham, J. A.; Vermaas, E. H.; Toole, J. J. Selection of SingleStranded DNA Molecules That Bind and Inhibit Human Thrombin. Nature 1992, 355, 564-566. 
[31] Yoshida, W.; Sode, K.; Ikebukuro, K. Homogeneous DNA Sensing Using EnzymeInhibiting DNA Aptamers. Biochem. Biophys. Res. Commun. 2006, 348, 245-252.

[32] Shiang, Y.-C.; Huang, C.-C.; Wang, T.-H.; Chien, C.-W.; Chang, H.-T. Aptamer-Conjugated Nanoparticles Efficiently Control the Activity of Thrombin. Adv. Funct. Mater. 2010, 20, 31753182.

[33] Zhang, D. Y.; Hariadi, R. F.; Choi, H. M. T.; Winfree, E. Integrating DNA StrandDisplacement Circuitry with DNA Tile Self-Assembly. Nat. Commun. 2013, 4, 1965.

[34] Rogers, W. B.; Manoharan, V. N. DNA Nanotechnology. Programming Colloidal Phase Transitions with DNA Strand Displacement. Science 2015, 347, 639-642. 


\section{SUPPORTING INFORMATION}

Sections

1. Materials and Methods

2. Supporting Figures

3. References 


\section{MATERIALS AND METHODS}

\subsection{Chemicals}

Phosphate buffered saline (PBS) tablets, magnesium chloride, potassium chloride, HEPES, $\mathrm{HCl}, \mathrm{NaOH}$ were all purchased from Sigma Aldrich (Merck KGaA, Darmstadt, Germany) and used as received. Recombinant human TATA binding protein TBP, recombinant human c-Myc protein and recombinant human MAX protein were supplied by Abcam (Cambridge, UK). Polyacrylamide and 6x Orange DNA Loading Dye were purchased from Termo Scientific ${ }^{T M}$. InstantBlue ${ }^{\circledR}$ Protein Gel Stain was supplied by Expedeon (Cambridge, UK). The thiazole orange dye binding to Mango, TO-1, is a pegylated and biotinylated thiazole orange molecule supplied by Applied Biological Materials Inc. (Richmond, BC). Human thrombin was purchased from Haematologic Technologies (Essex Junction, VT). Fibrinogen from human plasma was provided by Merck (Darmstadt, Germany).

\subsection{Oligonucleotides}

HPLC-purified oligonucleotides were purchased from IBA (Gottingen, Germany) or Eurofins Genomics (Luxembourg). The DNA probes were modified with Alexa Fluor 488 (AF488), Black Hole Quencher 2 (BHQ1), Cyanine 3 (Cy3) or Cyanine 5 (Cy5) at either the 3'or 5'-terminus, when appropriate. All oligonucleotides were dissolved in PBS $\mathrm{pH} 7.4$ at a concentration of $100 \mu \mathrm{M}$ and stored at $-20^{\circ} \mathrm{C}$. The DNA and RNA sequences are reported below. 
TBP-controlled DNA system

Bold: double stranded TBP-binding domain; underlined: toehold-binding domain; italic: invading domain.

\section{TBP-Translator 1}

5'- TACTTTTAAATATAAATAAGTGGTGATTTTTATATATTTTTTTTTCACAGAATGG CATAGGTCACG-3'

TBP-Translator 2

5'-TACTTTTATATAAATAAGTTGTGATTTTTATATATTTCACAGAATGGCATAGGTC ACG -3'

TBP-Translator 3

5' - TACCTTTATATAAATAGGTTGTGATTTTTATATATTTCACAGAATGGCATAGGT CACG -3'

TBP-Translator 4

5' - TACCTTTATATAAATAGGTTGTGAAATTTATATATTTCACAGAATGGCATAGGT CACG -3'

TBP-Translator 5

5' - TACCGTTATATAAATCGGTTGTGAAATTTATATATTTCACAGAATGGCATAGGT CACG -3'

\section{Reporter Duplex}

5'- (Cy5) - CGTGACCTATGCCATTCTGTGA -3'

5'- AGAATGGCATAGGTCACG - (Су3) - 3'

Single Stranded Invader (Control SS)

5'- TCACAGAATGGCATAGGTCACG - 3' 
Hairpin Invader (Control Hairpin)

5' - TACCTTTCCTATCCTTTTGGATAGGATTTCACAGAATGGCATAGGTCACG -3'

\section{TBP Inhibitor}

5' - ATATAAACCCCCTTTATAT - 3'

\section{Myc-Max-controlled DNA system}

Bold: double stranded Myc-Max-binding domain; underlined: toehold-binding domain; italic: invading domain.

MYX-Translator

5'-TAAATACCACGTGGTATTTTATGATGACCACGTGTTCATCATAGAATGGCATAG

GTCACG -3'

Reporter Duplex

5' - (Су5) - CGTGACCTATGCCATTCTATGATG - 3'

5'- AGAATGGCATAGGTCACG - (Су3) - 3'

Single Stranded Invader (Control SS)

5'- CATCATAGAATGGCATAGGTCACG - 3'

Hairpin Invader (Control Hairpin)

5' - TAAATACCCTACTACTTTTGTAGTAGGTTCATCATAGAATGGCATAGGTCACG -3'

Myc-Max Inhibitor

5'- CACGTGGTTTTTACCACGTG -3'

\section{Multi-input DNA network}

Bold: double stranded protein-binding domain; underlined: toehold-binding domain; italic: invading domain 
TBP-Translator

5' - TACCTTTATATAAATAGGTTGTGATTTTTATATATTTCACAGATTGCCATAGG

TCAGC -3

TBP Reporter Duplex

5'- (BHQ1) - GCTGACCTATGGCAATCTGTGA - 3'

5' - AGATTGCCATAGGTCAGC - (AF488) - 3'

MYX-Translator

5'-TAAATACCACGTGGTATTTTATGATGACCACGTGTTCATCATAGAATGGCATAG

GTCACG -3'

Myc-Max Reporter Duplex

5' - (Cy5) - CGTGACCTATGCCATTCTATGATG -3'

5'- AGAATGGCATAGGTCACG - (Су3) - 3'

RNA Mango activation system

Bold: double stranded TBP-binding domain; underlined: toehold-binding domain; italic:

invading domain

TBP-Mango-Translator

5' - TACCTTTATATAAATAGGTTGTGAAATTTATATATTTCACTAATCGTGATAGG -3'

Mango III RNA aptamer

5' - UAAUCGUGAUAGGAAGGAUUGGUAUGUGGUAUAUAUCACG - 3'

RNA blocking strand

5' - CCUAUCACGAUUAGUGA - 3'

DNA hairpin invader

5' - TACCTTTCCTATCCTTTTGGATAGGATTTCACTAATCGTGATAGG -3' 


\section{Thrombin regulation system}

Bold: double stranded TBP-binding domain; underlined: aptamer stem-loop domain; italic: invading domain

\section{TBP-Thrombin-Translator}

5'- TACCTTTATATAAATAGGTAGTGATTTTTATATATTTCACAAGTAAGCATTC -3'

Stem-loop-modified thrombin DNA aptamer

5' - CACTGGTAGGTTGGTGTGGTTGCGGAGAATGCTTACTTGTGATCCGCTTGGG

GCCAGTG -3'

\section{Aptamer-invading DNA hairpin}

5'- TACCTTTCCTATCCTTTTGGATAGGATTTCACAAGTAAGCATTC -3'

\subsection{TBP-actuated DNA strand displacement}

\subsubsection{Fluorescence measurements}

Five different TBP-responsive DNA translators (TBP-Translators) were engineered as double-stem-loop hairpin structures in which the two loops encode the double stranded consensus sequence recognized by TBP and one of the two stems incorporates the inactivated toehold-binding region of an input strand. This structure is in thermodynamic equilibrium with another mutually exclusive single-stem-loop hairpin conformation in which the stem is the full double stranded TBP consensus sequence and the input strand is free to initiate a strand displacement reaction (Figure 2a). When TBP recognizes its specific consensus sequence and binds to the DNA translator, the thermodynamic equilibrium shifts towards this latter "active" conformation through a population-shift mechanism. ${ }^{[1,2]}$ For each of the five translators, the predicted standard free energies of the two switching conformations were determined in silico using the freely available OligoAnalyzer ${ }^{\circledR}$ tool developed by 
Integrated DNA Technologies (IDT), setting $\mathrm{T}=37^{\circ} \mathrm{C},\left[\mathrm{Na}^{+}\right]=200 \mathrm{mM},\left[\mathrm{Mg}^{2+}\right]=5 \mathrm{mM}$. Based on these values, it was possible to calculate the predicted intrinsic switching equilibrium constant $\left(\mathrm{K}_{\mathrm{S}}\right)$ of each of the TBP-Translators using the standard thermodynamic equation $\Delta \mathrm{G}$ $=-R T \cdot \ln (K)$. TBP-induced strand displacement reactions were monitored over 120 minutes through fluorescence measurements. The reporter duplex (30 nM) was formed by hybridizing equimolar concentrations of the two relevant strands in PBS pH 7.4 supplemented with $\left[\mathrm{Mg}^{2+}\right]$ $=5 \mathrm{mM}$ and incubating at $\mathrm{T}=37^{\circ} \mathrm{C}$, until complete stabilization of the Cy3 fluorescence signal. Fluorescence kinetic measurements were carried out on a Cary Eclipse Fluorimeter (Varian) using quartz cuvettes of reduced volume $(100 \mu \mathrm{L})$. Working wavelengths were set to $\lambda_{\mathrm{exc}}=545 \mathrm{~nm}$ and $\lambda_{\mathrm{em}}=565 \mathrm{~nm}$ to monitor the Cy 3 fluorescence signal and all measurements were performed at $\mathrm{T}=37^{\circ} \mathrm{C}$. The strand displacement kinetic profiles were obtained by initially mixing TBP $(300 \mathrm{nM})$ with the reporter duplex and by adding the relevant TBPTranslator $(30 \mathrm{nM})$ after 10 minutes of baseline acquisition. Background fluorescence measurements were carried out analogously, but without addition of TBP. The fluorescence intensities recorded in the presence (+ TBP) and absence (Background, Bkg) of TBP were used to calculate the following outputs:

$\Delta$ Signal Gain $\%=\left[\left(\frac{I_{T B P}-I_{\text {start }}}{I_{\text {start }}}\right) * 100\right]-\left[\left(\frac{I_{B k g}-I_{\text {start }}}{I_{\text {start }}}\right) * 100\right] \quad$ (Figure 2d)

Signal Gain $\%=\left(\frac{I_{T B P}-I_{B k g}}{I_{B k g}}\right) * 100 \quad$ (Figure SI2)

Signal-to-Noise $(\mathrm{S} / \mathrm{N})=\frac{I_{T B P}}{I_{B k g}} \quad($ Figure SI2) 
where $\mathrm{I}_{\mathrm{TBP}}$ is fluorescence intensity obtained upon addition of TBP-Translator in the presence of TBP; $I_{B k g}$ is the background fluorescence intensity obtained upon addition of the TBPTranslator in the absence of TBP; $I_{\text {start }}$ is the initial fluorescence intensity generated by the reporter duplex.

TBP-concentration-dependent strand displacement reactions (Figure 2e) were conducted following the same protocol, using TBP-Translator 3 as the TBP-responsive translator and varying the concentration of TBP in the working solution $(100-300 \mathrm{nM})$. The control experiments aimed at determining the relative efficiency of the TBP-actuated strand displacement reaction were carried out using $30 \mathrm{nM}$ of either a single stranded input sequence or a hairpin structure mimicking the TBP-Translator active conformation when bound to TBP. The signal gain obtained using TBP-Translator 3 in the presence of TBP $300 \mathrm{nM}$ was taken as a reference and normalized to 1 ; the other fluorescence signals were scaled accordingly for comparison (Figure 2f). Inhibition of TBP-binding activity (Figure SI3) was achieved by preincubating TBP $(300 \mathrm{nM})$ with a DNA hairpin inhibitor $(3 \mu \mathrm{M})$ directly in the reporter duplexcontaining solution (30 nM), followed by addition of TBP-Translator $3(30 \mathrm{nM})$ after 10 minutes of incubation. Cross-reactivity experiments (Figure SI5) were conducted under the same conditions described above, using Myc-Max (300 nM) instead of TBP.

\subsubsection{Gel electrophoresis}

A native polyacrylamide gel (10\%) was used to monitor the binding dynamics of the TBPinduced strand displacement network. An aliquot of $10 \mu$ of each sample (see Figure SI3) was mixed with 2uL of 6x Orange DNA Loading Dye (Thermo Fischer Scientific) and loaded into the gel. The native PAGE was performed in a Mini-PROTEAN Tetra cell electrophoresis unit 
(Bio-Rad) at room temperature using $1 \times$ TBE buffer at $\mathrm{pH} 8.3$ and at a constant voltage of $90 \mathrm{~V}$ for $1 \mathrm{~h}$ (using Bio-Rad PowerPac Basic power supply). To visualize DNA bands, a $30 \mathrm{~min}$ staining with $1 \times$ SYBR gold (Invitrogen) in $1 \times$ TBE buffer was applied. The gel was imaged under a Gel Doc XR+ system (Bio-Rad). To visualize TBP, the gel was subsequently stained with InstantBlue ${ }^{\circledR}$ Protein Gel Stain, according to the manufacturer's instruction. Briefly, $40 \mathrm{~mL}$ of staining solution were added to the gel, which was imaged under the Gel Doc XR+ System once the bands had become visible at naked eye.

\subsection{Myc-Max-actuated DNA strand displacement}

All the fluorescence measurements were carried out under the same conditions used with the TBP-controlled strand displacement system. Myc-Max, which is a transcription factor complex composed of two proteins, was formed by mixing together human c-Myc and MAX at the desired final concentration. Cross-reactivity experiments were conducted by exposing the MYX-Translator to TBP instead of Myc-Max.

\subsection{Multi-input DNA networks}

The reporter duplexes of the TBP- and Myc-Max-controlled systems were formed separately and then mixed together at a final concentration of $30 \mathrm{nM}$ each in PBS pH 7.4 supplemented with $\left[\mathrm{Mg}^{2+}\right]=5 \mathrm{mM}$. Fluorescence spectra (Figure SI9) were acquired in two distinct emission windows relative to the two reporter dyes: $\lambda_{\mathrm{exc}}=488 \mathrm{~nm}$ and $\lambda_{\mathrm{em}}=550-550$ $\mathrm{nm}$ for AF488 (TPB system), $\lambda_{\mathrm{exc}}=538 \mathrm{~nm}$ and $\lambda_{\mathrm{em}}=550-600 \mathrm{~nm}$ for Cy3 (Myc-Max system). To perform orthogonal strand displacement reactions, the solution containing the two reporter duplexes was initially added, respectively: 1) TBP $100 \mathrm{nM}$; 2) Myc-Max $300 \mathrm{nM}$; 3) TBP 100 nM and Myc-Max 300 nM; 4) nothing (background experiment). TBP-Translator and 
MYX-Translator (30 $\mathrm{nM}$ each) were simultaneously added to the mixture after $10 \mathrm{~min}$. Following $1 \mathrm{~h}$ of incubation, fluorescence spectra were acquired using the instrumental settings described above and the intensity values at $\lambda_{\mathrm{em}}=516 \mathrm{~nm}$ (AF488) and $\lambda_{\mathrm{em}}=565 \mathrm{~nm}$ (Cy3) were taken as numerical outputs of the TBP- and Myc-Max-actuated reactions, respectively (Figure 3).

\subsection{Mango RNA network}

The Mango III RNA sequence used in our work is a recent version optimized for strand displacement-based applications. ${ }^{[3]}$ The Mango aptamer and its partially complementary RNA strand were mixed together (30 $\mathrm{nM}$ each) in $10 \mathrm{mM}$ HEPES $\mathrm{pH} 7.4$, supplemented with $\left[\mathrm{MgCl}_{2}\right]=5 \mathrm{mM}$ and $[\mathrm{KCl}]=100 \mathrm{mM}$ and incubated at $\mathrm{T}=37^{\circ} \mathrm{C}$ for $2 \mathrm{~h}$, in order to form a stable RNA complex (N.B. $\mathrm{Mg}^{2+}$ ions are necessary for TBP binding, while $\mathrm{K}^{+}$ions are required for Mango folding and binding to TO-1). The TO-1 dye (200 nM) was then added to the RNA solution. Fluorescence measurements were performed at $\mathrm{T}=37^{\circ} \mathrm{C}$, setting $\lambda_{\mathrm{exc}}=505 \mathrm{~nm}$ and $\lambda_{\mathrm{em}}=535 \mathrm{~nm}$ as working wavelengths. Preliminary Mango activation studies were conducted by adding to the above RNA complex/TO-1 solution a model DNA hairpin invader ( $20 \mathrm{nM}-300$ $\mathrm{nM})$ and monitoring over time $(60 \mathrm{~min})$ the increase in fluorescence signal. TBP-controlled Mango activation was achieved by including TBP $(600 \mathrm{nM})$ in the initial RNA complex/TO-1 solution and adding TBP-Mango-Translator (100 nM) after 5 minutes of baseline acquisition. Background fluorescence measurements were carried out analogously, but without adding TBP.

\subsection{Thrombin network}

The DNA thrombin aptameric structure used in our work was engineered by integrating the well-characterized 15-mer thrombin aptamer with a stem-loop handle that determines the 
stability of the G-quadruplex structure of the thrombin aptamer portion, following the molecular design rules reported by Ikebukuro and coworkers. ${ }^{[4]}$ The 15-mer thrombin DNA aptamer binds to the exosite 1 on thrombin with affinity in the low nanomolar range and, in doing so, it hampers the interaction with the thrombin natural substrate, fibrinogen. As a result, the proteolytic conversion of fibrinogen into fibrin (coagulation process) is inhibited. Preliminary evaluation of inhibition activity was carried out by incubating thrombin (1 nM) with the aptameric structure $(50 \mathrm{nM})$ for $1 \mathrm{~h}\left(\mathrm{~T}=37^{\circ} \mathrm{C}\right.$, PBS pH 7.4 supplemented with $\left[\mathrm{MgCl}_{2}\right]=5$ $\mathrm{mM}$ ), followed by addition of fibrinogen $(1 \mathrm{mg} / \mathrm{mL})$. The formation and aggregation of insoluble fibrin resulting from thrombin enzymatic activity was monitored by recording the increase in intensity of light scattering, which correlates with the increase in the turbidity of the solution. ${ }^{[5]}$ Measurements were carried out on a Cary Eclipse Fluorimeter (Varian) using working wavelengths of $\lambda_{\mathrm{exc}}=600 \mathrm{~nm}$ and $\lambda_{\mathrm{em}}=610 \mathrm{~nm}$ with slits exc/em both $10 \mathrm{~nm}$. To modulate thrombin enzymatic activity, varying concentrations $(10-500 \mathrm{nM})$ of a model aptamersequestering DNA hairpin sequence were added to the solution containing the inhibited thrombin/aptamer complex. TBP-controlled regulation of thrombin activity was achieved by incubating together thrombin $(1 \mathrm{nM})$, the aptameric structure $(50 \mathrm{nM})$, TBP-ThrombinTranslator $(50 \mathrm{nM})$ and TBP $(300 \mathrm{nM})$, followed by addition of fibrinogen $(1 \mathrm{mg} / \mathrm{mL})$.

\subsection{Data analysis}

Data plotting and statistical description were carried out on Prism8 (GraphPad). The experimental results reported in the bar graphs are the average of three independent replicates + standard error of the mean (SEM). 


\section{SUPPORTING FIGURES}

\begin{tabular}{|c|c|c|c|c|c|c|c|c|c|c|c|c|}
\hline & & & \multicolumn{10}{|c|}{ TBP-Translator } \\
\hline & & & \multicolumn{2}{|c|}{1} & \multicolumn{2}{|r|}{2} & \multicolumn{2}{|r|}{3} & \multicolumn{2}{|r|}{4} & \multicolumn{2}{|r|}{5} \\
\hline & & & bp & $\%$ GC & bp & $\% G C$ & bp & $\% \mathrm{GC}$ & bp & $\% G C$ & bp & $\% \mathbf{G C}$ \\
\hline \multirow[t]{6}{*}{ Loop 1} & Loop 2 & \multirow{3}{*}{ Stem $\left[\begin{array}{l}1 \\
2\end{array}\right.$} & 4 & 25 & 4 & 25 & 4 & 50 & 4 & 50 & 4 & 75 \\
\hline & & & 4 & 50 & 4 & 50 & $\begin{array}{l}1 \\
1\end{array}$ & 50 & 7 & 29 & 7 & 29 \\
\hline & & & \multicolumn{6}{|c|}{ lenght (nt) lenght (nt) lenght (nt) } & leng & ght (nt) & \multicolumn{2}{|c|}{ lenght (nt) } \\
\hline & & \multirow{2}{*}{ Loop } & & 12 & & 10 & & 10 & & 10 & & \\
\hline & & & & 18 & 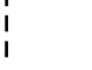 & 12 & 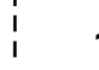 & 12 & 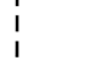 & 6 & 1 & 6 \\
\hline & & $K_{\mathrm{S}}$ & & .4 & & 1.4 & & .4 & & .02 & & 002 \\
\hline
\end{tabular}

Figure SI1. Sequence and structural parameters of the stem and loop domains of the five TBP-Translators $(\mathrm{bp}=$ base pairs, $\mathrm{nt}=$ nucleotides $)$. 
a

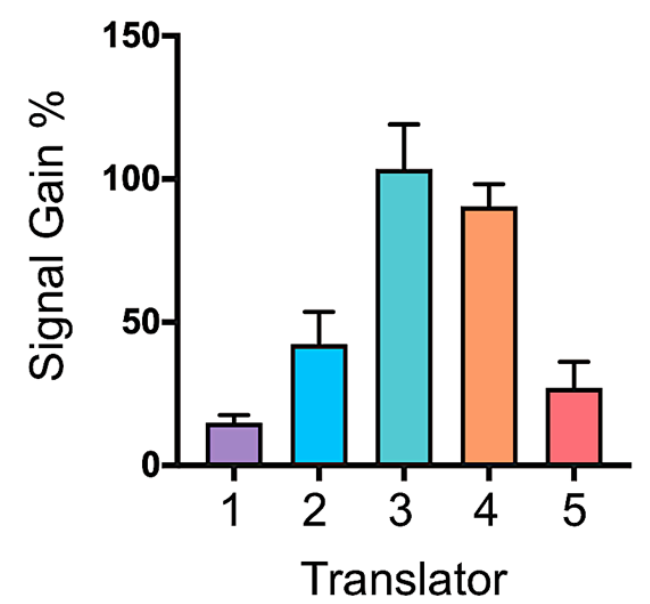

b

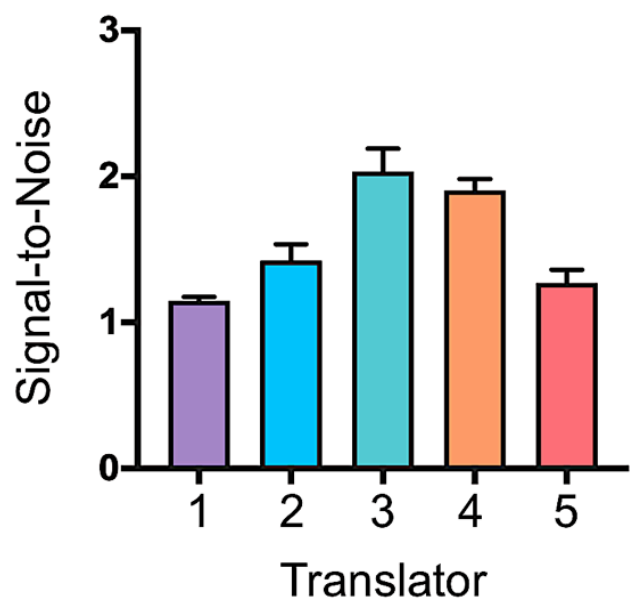

Figure SI2. (a) TBP-controlled strand displacement Signal gain \% and (b) Signal-to-noise ratio provided by the different TBP-Translators $(n=3$, mean + standard error of the mean, SEM). 

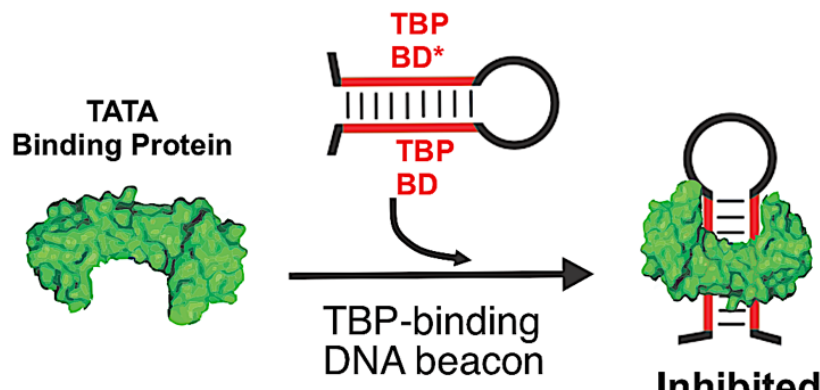

Inhibited

TBP

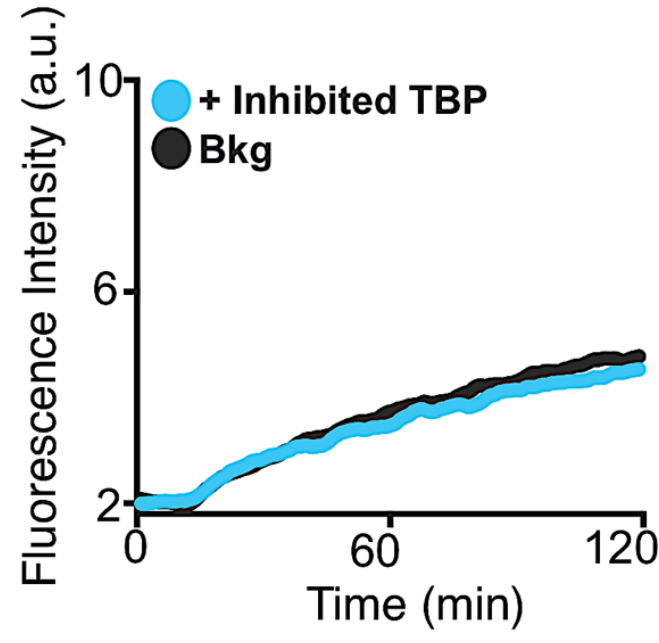

Figure SI3. When TBP $(300 \mathrm{nM})$ is pre-incubated with a DNA hairpin bearing the complete TBP-binding domain (TBP BD, red portion in the hairpin structure) $(3 \mu \mathrm{M})$, further binding activity is inhibited and the kinetic profile of TBP-induced strand displacement using TBPTranslator $3(30 \mathrm{nM})$ is undistinguishable from that of the background. 


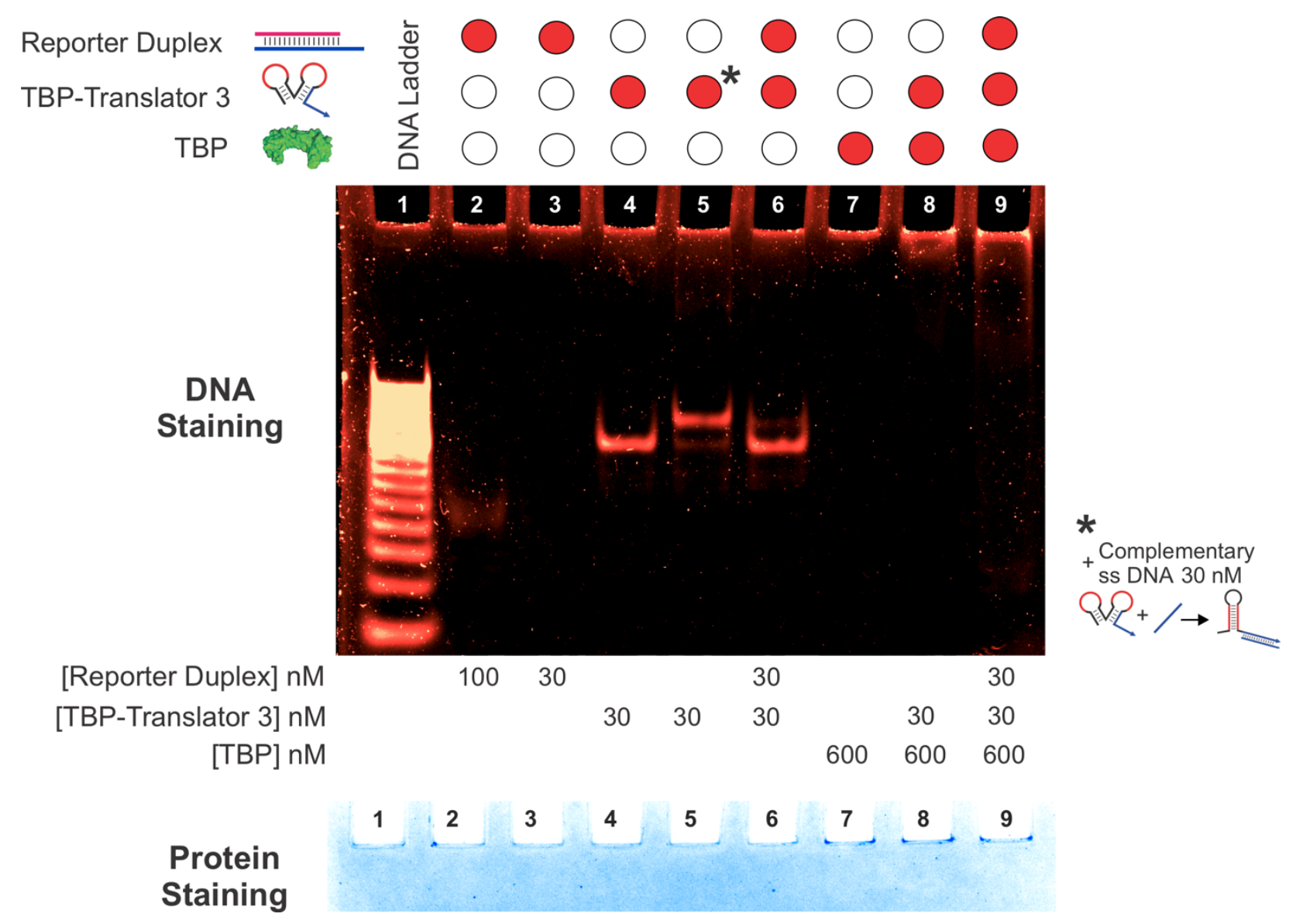

Figure SI4. TBP-actuated strand displacement was monitored through non-denaturing $10 \%$ PAGE analysis of the mono- and multi-molecular species involved. Each lane is representative of a sample incubated at $\mathrm{T}=37^{\circ} \mathrm{C}$ for $1 \mathrm{~h}$; the concentration of each species is reported in the figure. Gel lanes: 1) 5 bp DNA ladder; 2) reporter duplex (higher concentration as reference); 3) reporter duplex (working concentration); 4) TBP-Translator 3; 5) TBP-Translator $3+$ the toehold-bearing strand of the reporter duplex; 6) reporter duplex + TBP-Translator 3; 7) TBP only; 8) TBP-Translator $3+$ TBP; 9) reporter duplex + TBP-Translator $3+$ TBP. The top panel shows the bands obtained upon DNA staining with SYBR gold; the bottom panel reports the bands obtained upon protein staining with InstantBlue® Protein Gel Stain. Lanes 8, 9 show 
association of TBP with TBP-Translator 3, and of TBP with the final TBP-Translator 3/DNA complex reported in lane 5 , respectively. 


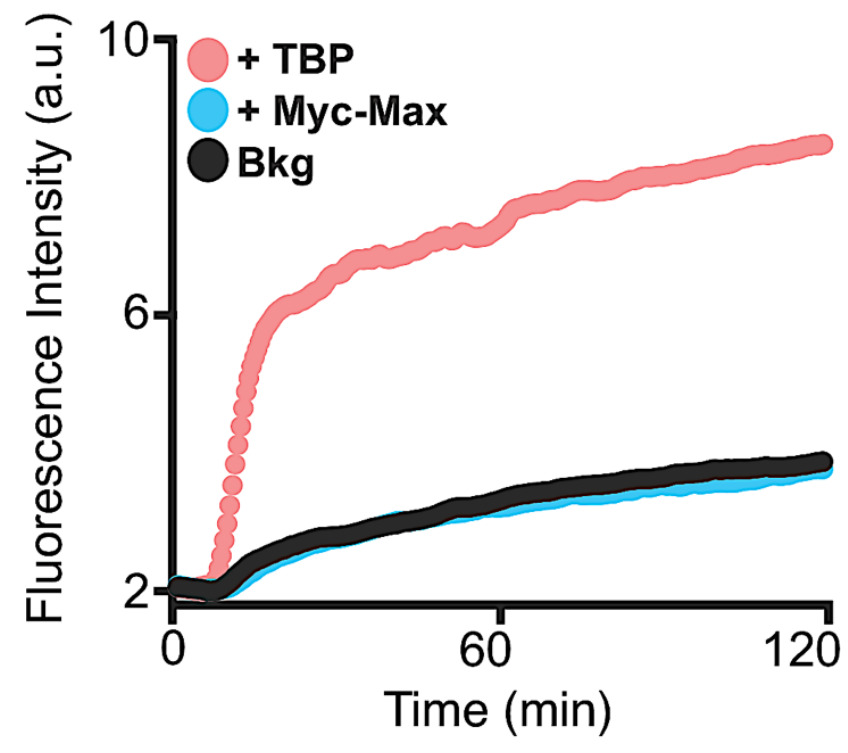

Figure SI5. Specificity test. When the TBP-Translator $3(30 \mathrm{nM})$ is exposed to Myc-Max (300 $\mathrm{nM}$ ), the kinetic profile of the resulting strand displacement reaction is not significantly different from that of the background. 

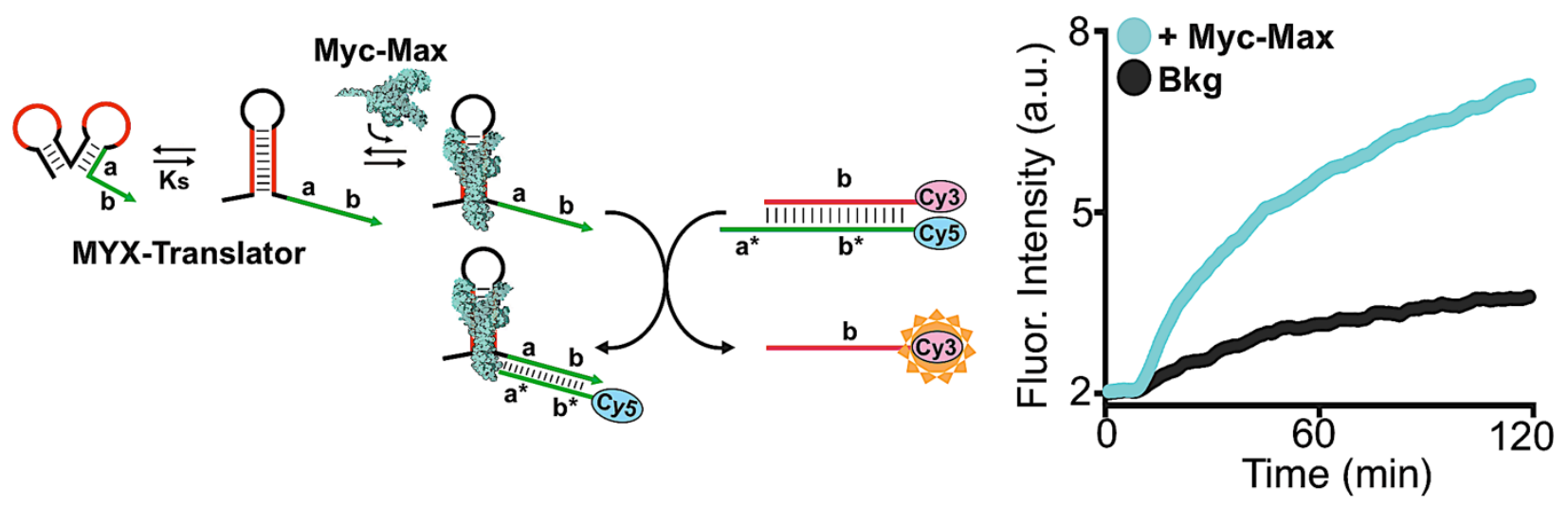

Figure SI6. DNA strand displacement actuated by Myc-Max binding to and activating a specific DNA translator (MYX-Translator). Kinetic profiles of strand displacement reactions in the presence (+Myc-Max) or absence $(\mathrm{Bkg})$ of Myc-Max (300 nM) obtained in an equimolar concentration solution of MYX-Translator and reporter duplex (30 nM). Myc-Max-controlled strand displacement gave $\Delta$ Signal Gain $\%=169 \pm 39$, Signal Gain $\% 99 \pm 38$ and $S / N=2.0 \pm$ $0.4(n=3$, mean + SEM) 

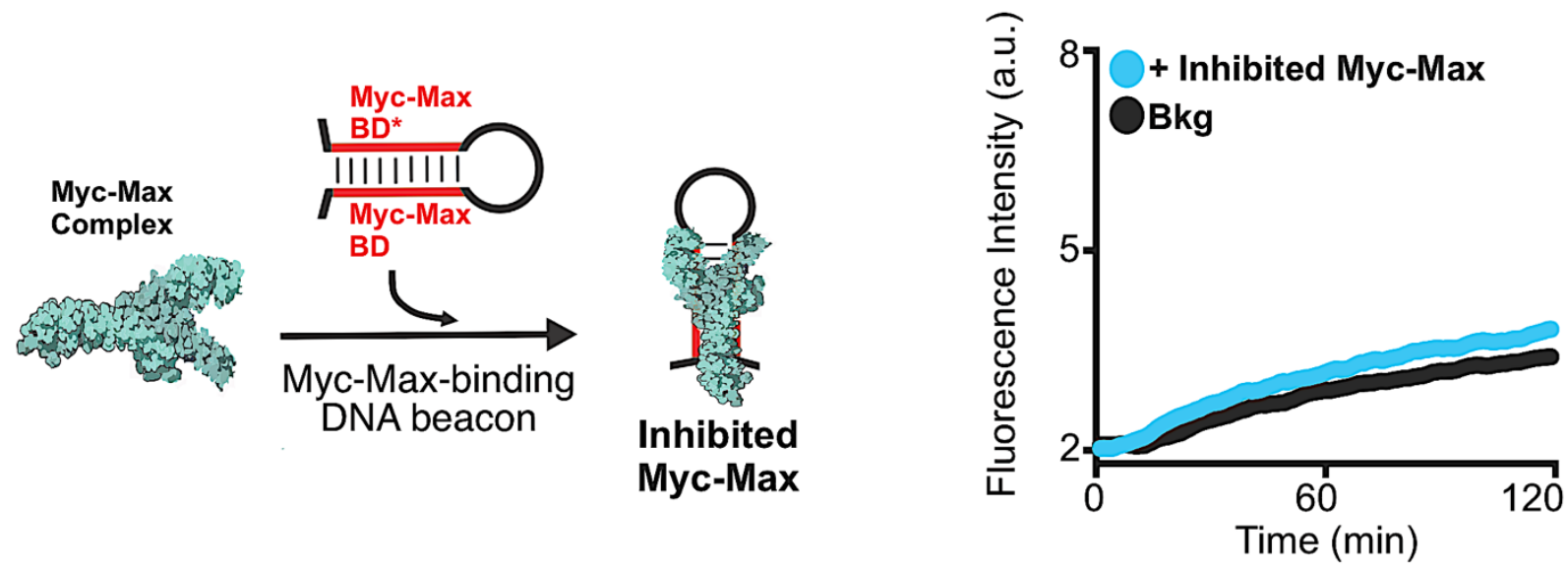

Figure SI7. When Myc-Max (300 nM) is pre-incubated with a DNA hairpin bearing the complete Myc-Max-binding domain (Myc-Max BD, red portion in the hairpin structure) ( $3 \mu \mathrm{M})$, further binding activity is inhibited and the kinetic profile of Myc-Max-induced strand displacement using MYX-Translator (30 nM) is undistinguishable from that of the background. 


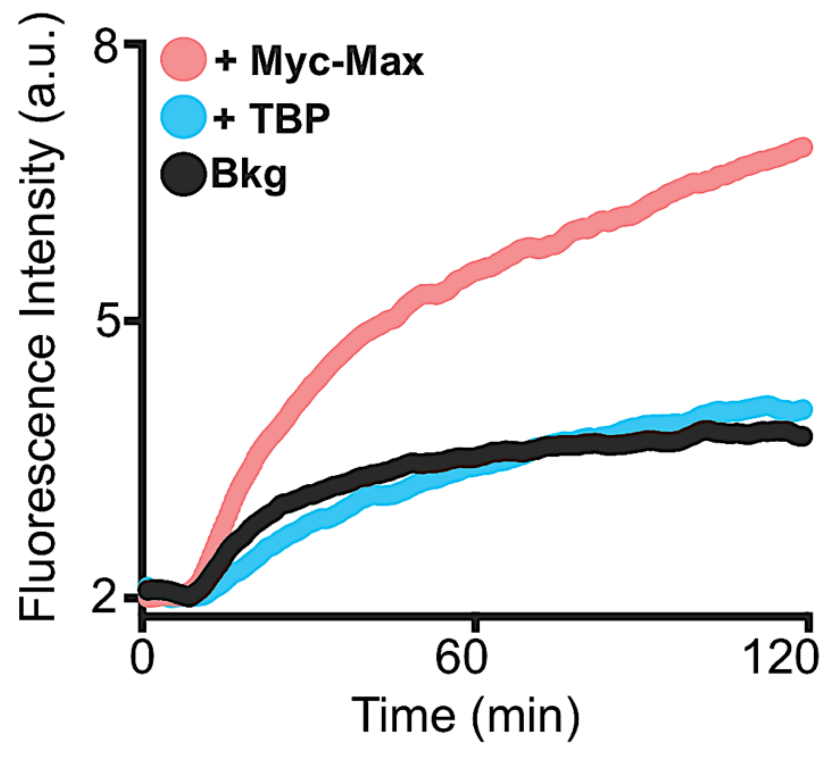

Figure SI8. Specificity test. When MYX-Translator (30 nM) is exposed to TBP (100 nM), the kinetic profile of the resulting strand displacement reaction is not significantly different from that of the background 

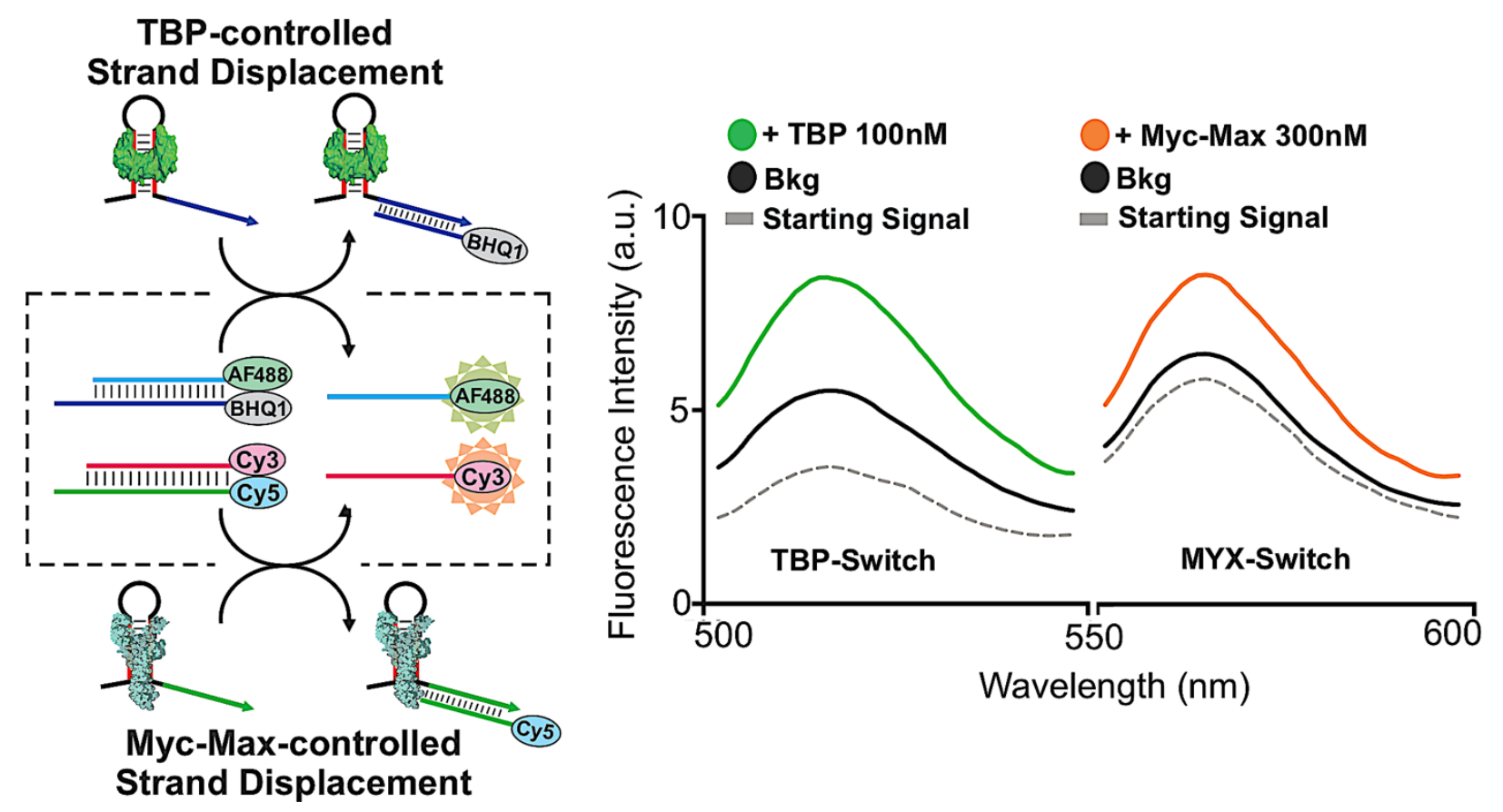

Figure S19. Orthogonal, protein-controlled strand displacement reactions. Left) Schematic representation of the multi-input molecular network. Right) Representative fluorescence emission spectra relative to 1) TBP-responsive reaction network in the emission window $\lambda_{\mathrm{em}}=$ $550-550$ nm (AF488). "Starting signal" = reporter duplex 30 nM; "Bkg" = reporter duplex 30 $\mathrm{nM}+$ TBP-Translator $30 \mathrm{nM}, \mathrm{t}=60$ min; "+ TBP $100 \mathrm{nM}$ " = reporter duplex $30 \mathrm{nM}+$ TBPTranslator $30 \mathrm{nM}+$ TBP $100 \mathrm{nM}, \mathrm{t}=60 \mathrm{~min}$; 2) Myc-Max-responsive reaction network in the emission window $\lambda_{\mathrm{em}}=550-600 \mathrm{~nm}$ (Сy3). "Starting signal" = reporter duplex $30 \mathrm{nM}$; "Bkg" = reporter duplex $30 \mathrm{nM}$ + MYX-Translator $30 \mathrm{nM}, \mathrm{t}=60 \mathrm{~min}$; "+ Myc-Max 300 nM" = reporter duplex $30 \mathrm{nM}+$ MYX- ranslator $30 \mathrm{nM}+$ Myc-Max $300 \mathrm{nM}, \mathrm{t}=60 \mathrm{~min}$. 

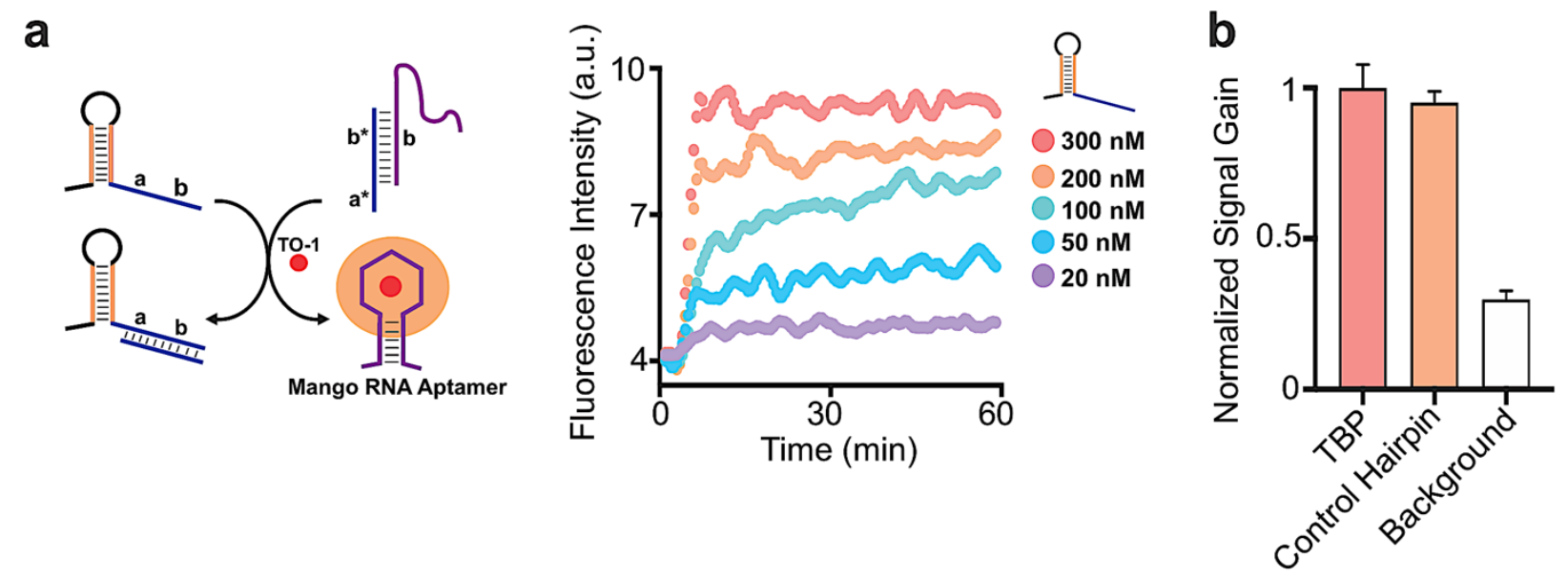

Figure SI10. a) Strand displacement-based activation of a fluorogenic Mango RNA aptamer. Correct folding of Mango into its optically active conformation is prevented by an RNA strand that hybridizes with a critical region of the aptamer. Upon strand displacement, the Mango aptamer can properly fold into its functional structure and bind to its fluorophore ligand TO-1, generating a fluorescence signal. The graph shows the kinetic profiles of Mango activation obtained when the initial inactive RNA complex (30 nM) is added varying concentrations (20$300 \mathrm{nM}$ ) of a DNA hairpin sequence that triggers the strand displacement process. (b) The signal gain resulting from TBP-controlled activation of Mango (TBP $600 \mathrm{nM}$, TBP-MangoTranslator $100 \mathrm{nM}$, RNA complex $30 \mathrm{nM}$ ) is not significantly different from that obtained using the model DNA hairpin invader at the same concentration $(n=3$, mean + SEM). The signal gain of the TBP-controlled system is taken as a reference and normalized to 1 ; the other signals are scaled accordingly for comparison. 
a
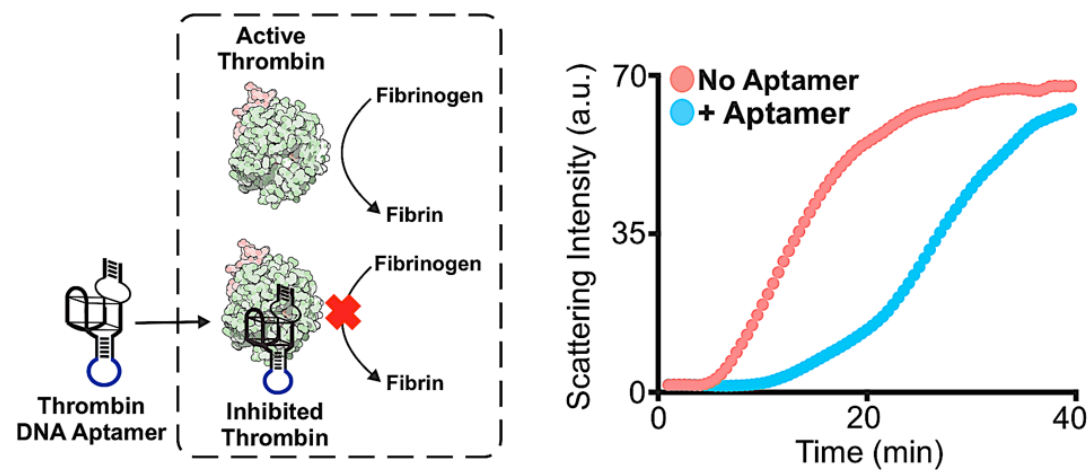

b
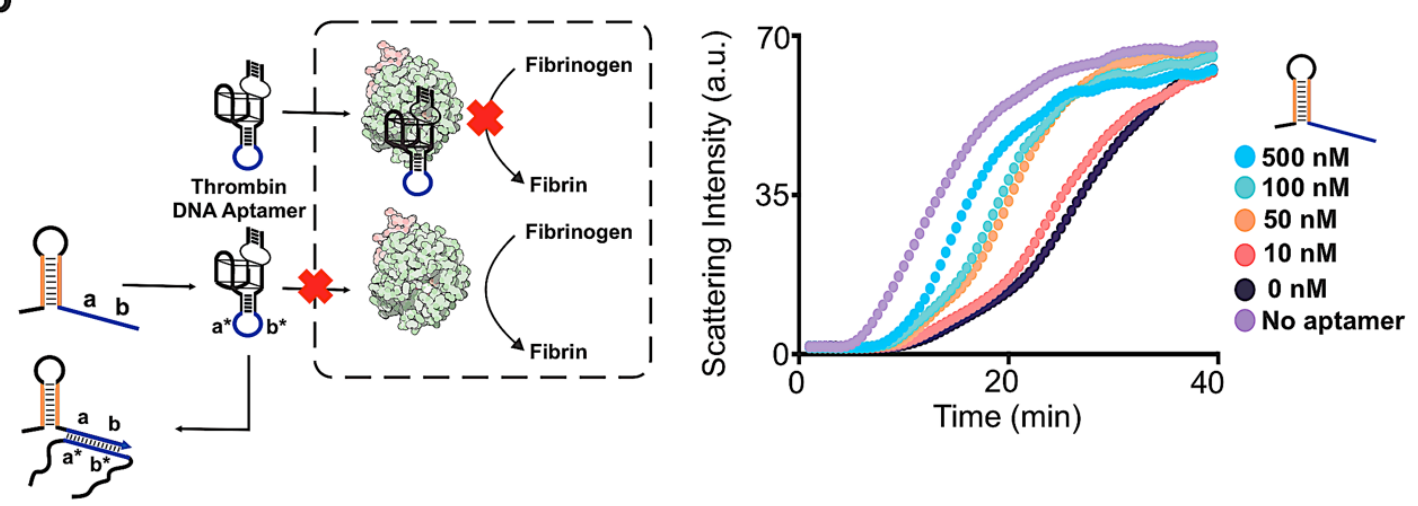

C

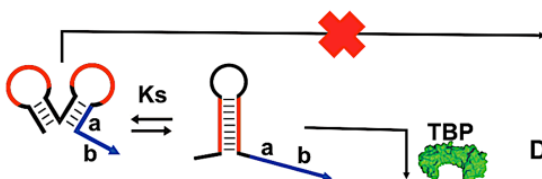

TBP-Thrombin-Translator
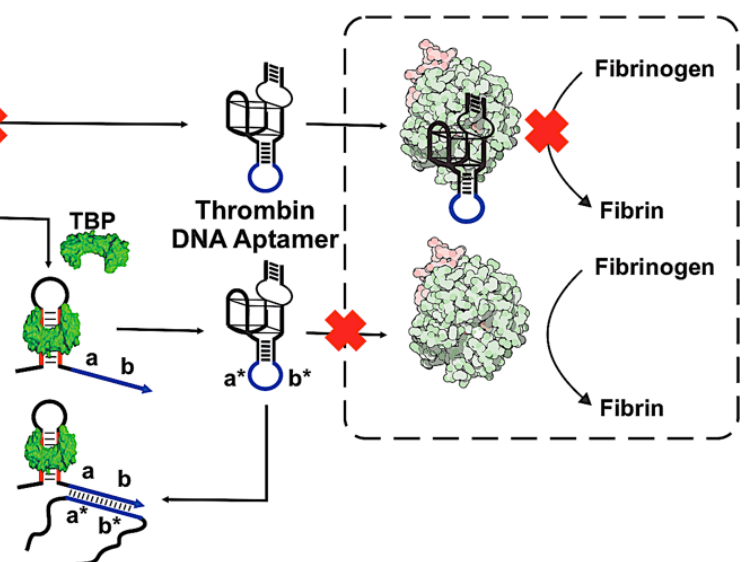

Figure SI11. (a) The stem-loop-modified DNA thrombin aptamer prevents the proteolytic conversion of fibrinogen into fibrin by binding to the exosite 1 on thrombin. The intensity of light scattering is correlated with the increase in the turbidity of the solution due to thrombinmediated fibrin formation and agglomeration. Light scattering intensity is reported as a function of time upon fibrinogen $(1 \mathrm{mg} / \mathrm{mL})$ addition to thrombin $(1 \mathrm{nM})$ in the presence (+ Aptamer) or 
absence (No Aptamer) of the aptameric structure (50 nM). (b) The addition of different concentrations $(0-500 \mathrm{nM})$ of a model DNA hairpin designed to open the stem-loop portion of the aptameric structure allows for modulating thrombin enzymatic activity. (c) Schematic overview of the whole molecular network in which the enzymatic activity of thrombin is upstream regulated by TBP through the use of a TBP-responsive DNA translator, TBPThrombin-Translator. 


\section{REFERENCES}

[1] Vallée-Bélisle, A.; Bonham, A. J.; Reich, N. O.; Ricci, F.; Plaxco, K. W. Transcription Factor Beacons for the Quantitative Detection of DNA Binding Activity. J. Am. Chem. Soc. 2011, 133, 13836-13839

[2] Vallée-Bélisle, A.; Ricci, F.; Plaxco, K. W. Thermodynamic Basis for the Optimization of Binding-Induced Biomolecular Switches and Structure-Switching Biosensors. Proc. Natl. Acad. Sci. USA 2009, 106, 13802-13807.

[3] Zhong, W.; Sczepanski, J. T. A Mirror Image Fluorogenic Aptamer Sensor for Live-Cell Imaging of MicroRNAs. ACS Sens. 2019, 4, 566-570.

[4] Yoshida, W.; Sode, K.; Ikebukuro, K. Homogeneous DNA Sensing Using EnzymeInhibiting DNA Aptamers. Biochem. Biophys. Res. Commun. 2006, 348, 245-252.

[5] Shiang, Y.-C.; Huang, C.-C.; Wang, T.-H.; Chien, C.-W.; Chang, H.-T. AptamerConjugated Nanoparticles Efficiently Control the Activity of Thrombin. Adv. Funct. Mater. 2010, 20, 3175-3182. 
